\title{
Asfalt Kaplama Kalınlığının Karışım Homojenitesi Üzerindeki Etkisi
}

\author{
Effect of Asphalt Pavement Thickness on Mixture Homogeneity
}

\author{
Erol İSKENDER* \\ Karadeniz Teknik Üniversitesi, Of Teknoloji Fakültesi, İnşaat Mühendisliği Bölümü, 61830, Trabzon
}

\author{
• Geliş tarihi / Received: 18.02.2019 • Düzeltilerek geliş tarihi / Received in revised form: 17.06.2019 • Kabul tarihi / Accepted: 01.07 .2019
}

$\ddot{O} \mathbf{z}$

Asfalt kaplamalarda karışım homojenitesi kaplama performansı ve ömrü üzerinde önemli rol oynamaktadır. Karışım homojenitesi çeşitli yöntemlerle değerlendirilebilmektedir. Bu yöntemlerden bir tanesi de ekstraksiyon metodudur. Bu çalışmada kaplama kalınlığının karışım homojenitesi üzerindeki etkisi araştırılımıştır. Uygulama sahasından alınan karot örnekleri yoğunluk, bitüm içeriği ve gradasyon değerleri açısından kaplama kalınlığa bağlı olarak değerlendirilmiştir. Karot örneklerinin yoğunluklarının tasarım yoğunluğunun üzerinde olduğu ve kalınlık arttıkça yoğunluğun azaldığı görülmüştür. Ancak kaplama kalınlığı $6.5 \mathrm{~cm}$ 'yi geçtikten sonra yoğunluk değerlerindeki azalma hızlanmıştır. Kaplama kalınlığı ile bitüm içeriği arasında yüksek korelasyonlu bir ilişki kurulamamıştır. Fakat karot örneklerinin ortalama bitüm içeriği, tasarım bitüm içeriğinden $\% 0.2$ daha büyük çıkmıştır. Kaplama kalınlığı değişse de agrega gradasyonları birbirine çok yakın gerçekleşmiş, tasarım gradasyonuna göre en büyük bozulma $0.18 \mathrm{~mm}$ ile $2.0 \mathrm{~mm}$ elekler arasında gerçekleşmiş̧ir.

Anahtar kelimeler: Asfalt kaplama, ekstraksiyon yöntemi, homojenite, tabaka kalınlığı

\begin{abstract}
Mixture homogeneity of wearing course in the asphalt pavements plays an important role in pavement performance and life. Mixture homogeneity can be evaluated by various methods. One of these methods is the extraction method. In this study, effect of asphalt pavement thickness on homogeneity was investigated. Core samples taken from actual asphalt pavement were evaluated in terms of density, bitumen content and gradation values depend on pavement thickness. It was observed that the density values of the core samples were above the design density and the density decreased with increasing pavement thickness. However, after the pavement thickness exceeded $6.5 \mathrm{~cm}$, the decrease in density values accelerated. High coefficient correlation was not found between pavement thickness and bitumen content. However, the average bitumen content of the core samples was $0.2 \%$ greater than the design bitumen content. Although the pavement thickness changed, the aggregate gradations were very close to each other and the highest distortion according to the design gradation was between $0.18 \mathrm{~mm}$ and $2.0 \mathrm{~mm}$ sieves.
\end{abstract}

Keywords: Asphalt pavement, homogeneity, pavement thickness, extraction method 


\section{Giriş}

Yol yapım şirketleri ve ilgili idareler inşaat süreci, kaynakların ve işin planlanması ve programlanmas1, kalite ve performans üzerinde daha etkili kontrol mekanizmaları geliştirmek için çalışmalarını sürdürmektedirler. Çünkü kaliteli kontrol, kaplamaların ekonomik ömrü içerisinde başarısızlık risklerini de azaltacaktır. Bu nedenle, sahadaki ilgili operasyonel parametrelerin bilinmesi ve bu parametreler arasındaki ilişkilerin iyice anlaşılması gerekir.

Asfalt kaplamalar laboratuvarda çok iyi tasarlanıp, bileşenleri oransal olarak kusursuz hesaplansalar bile uygulama aşamalarında çeşitli sorunlarla karşlaşlabilmektedir. Üstelik laboratuvar ortamında bile agrega köşeliliği ve gradasyonu gibi faktörler tam olarak kontrol altına alınamamaktadır. Uygulamada ise kaplama inşaa araçlarından, işçilikten veya hava koşullarının zorluğundan kaynaklanan problemler oluşabilmektedir. Asfalt karışımın sıkıştırılabilirliği, agrega gradasyonunun homojensizliği (segregasyon), termal homojensizlik, operasyonel hatalar kaplama kalınlığında farklılıklara neden olabilmektedir.

Literatürde, sıcak karışım asfalt (HMA) kaplamaların sıkıştırılabilirliğini etkileyen, malzeme sıcaklığı, bitüm içeriği ve agrega köşeliliği gibi farklı faktörlerin önemi vurgulanmıştır. Sıkıştırılabilirlik, bir karışımın belirli bir yoğunluğa sıkıştırılabileceği kolaylığın bir ölçüsüdür. Bir karışımın sıkıştırılabilirliğinin daha iyi olması durumunda, sahadaki asfalt karışımın hedef yoğunluğa sıkıştırılması da kolaylaşır. Rüzgar ve güneş gibi faktörler asfalt tabakanın sıkıştırılabilirliğini etkilemektedir. Ayrıca, HMA karışımlarının sıkıştırılması, kaliteye ulaşmada en önemli aşamalardan biri olarak görülmektedir. Mekanik malzeme davranış1 sıcaklığa bağlı olduğundan, asfalt karışımın sıcaklığındaki büyük değişikliklerin nihai sıkıştırılmış haldeki kaplamada farklılıklara neden olması mantıklıdır. $\mathrm{Bu}$ nedenle sicaklıktaki ve dolayısıyla sıkıştırma seviyelerindeki büyük farklılıklar, yapılan şeridin kalite tutarlılı̆̆ını bozar. Kalitenin iyileştirilmesi için karışım sıcaklığının homojenliğini geliştirmek ve sıcaksoğuk lekelerin oluşmaması için önlem almak gerekmektedir (ter Huerne vd., 2009).

Homojenlik, malzeme bileşenlerinin veya fazların dağılımını tanımlamak için sıklıkla kullanılan bir üniform olma durumu veya kalitesidir. Asfalt karışım homojenliği, bileşenlerinin (yani asfalt çimentosu, agregalar, katkı maddeleri ve hava boşlukları) dağılımına bağlıdır ve bunların arasında agrega dağılımı homojenliği belirlemede önemli bir rol oynar, çünkü diğer üç bileşenin asfalt karışım içerisindeki dağılımı genellikle agrega dağılımı tarafından belirlenir (Peng ve J. Sun, 2009).

Segregasyon veya üniformsuzluğu değerlendirmek için çeşitli yöntemler geliştirilmiştir. Doğrusal şekilli segregasyonları belirleyebilmek için ayrık nükleer yoğunluk ölçümleri (Wolff vd., 1997), yüzey segregasyonlarını belirleyebilmek için LASER (Meegoda vd., 2003), segregasyon varlığııı ve şiddet seviyesini belirlemek için infrared termograf ve ROSAN lazer yüzey doku ölçümleri (Stroup-Gardiner ve Brown, 2000), makro dokuyu değerlendirmek için ise dijital resim işleme teknikleri (Wang vd., 2004) kullanılmıştır.

Fakat yukarıda belirtilen yöntemlerin hasarsız ve uygulanması kolay olmasına rağmen bazı eksikliklerinin oldukları ifade edilmektedir. Örneğin, infrared termografi, lazer yüzey doku ölçümleri ve resimler yalnızca kaplamanın yüzeyini veya yüzeye yakın bir bölümünü değerlendirmede kullanılabilir. $\mathrm{Bu}$ yöntemlerle kaplama derinliği boyunca agrega dağ 1 lımı hakkında bilgi almak mümkün olmamaktadır (Peng ve J. Sun, 2009).

Sicak karışım asfaltlarda segregasyonun modellerle değerlendirildiği bir çalışmada (Stroup-Gardiner vd., 2000) segregasyon seviyesi, anahtar karışım özelliklerindeki değişiklik ve karışım yoğunluğu arasındaki ilişki araştırılmış ve segregasyon seviyesinin hava boşluğu, bitüm içeriği ve gradasyon gibi anahtar karışım özelliklerinden tahmin edilebileceği vurgulanmıştır.

Agrega gradasyonu asfalt karışımın içsel yapısını ve gerilme dağılımını etkilemektedir. Kaplama boyunca gradasyondaki değişiklikler homojensizliklere yol açmaktadır. Homojenite, mekanik dayanım ve yorulma ömrü gibi asfalt beton kaplamaların performansla ilgili birçok özelliğini etkiler. Yapılan araştırmalar, homojensizlikten dolayı çeşitli bozulmaların oluştuğunu ortaya koymuştur. Segregasyon veya üniformsuzluk olduğunda azalan rijitlik, çekme mukavemeti ve yorulma ömründen dolayı kaplamanın servis ömrü azalmaktadır (Sefidmazgi vd., 2012).

Asfalt karışımlarda agrega segregasyonu, güncel araştırma konularından biridir; çünkü segregasyon 
esas olarak homojensizliğe yol açar ve asfalt karışımının kaplama performansını, örneğin yorulma ömrünü, çekme mukavemetini ve su hasarına karşı direncini önemli ölçüde etkiler. Hatta asfalt kaplamanın servis ömrünün, agrega segregasyonu nedeniyle \%10'dan \%50'ye kadar azalabileceği ifade edilmektedir (Zhang vd., 2017).

$\mathrm{Bu}$ tür karışım homojensizlikleri asfalt karışımın sıkıştırılabilirliğini etkilemekte ve farklı kaplama kalınlıklarının ortaya çıkmasına neden olabilmektedir. Asfalt kaplama ve temel tabakalarının kalınlığının etkisinin araştırıldığı bir çalışmada, farklı kalınlık değişkenleri ile deneme yol kesimleri üretilerek ölçümler yapılmıştır. Ortaya çıkan sonuçlar, kaplama kalınlığının sabit olduğu seçeneklerde bile düşey deformasyonların değişken olduğunu bununla birlikte kaplama kalınlığının artmasıyla deformasyon miktarının azaldığını ortaya koymaktadır (Şekil 1.) (He ve Yang, 2018).

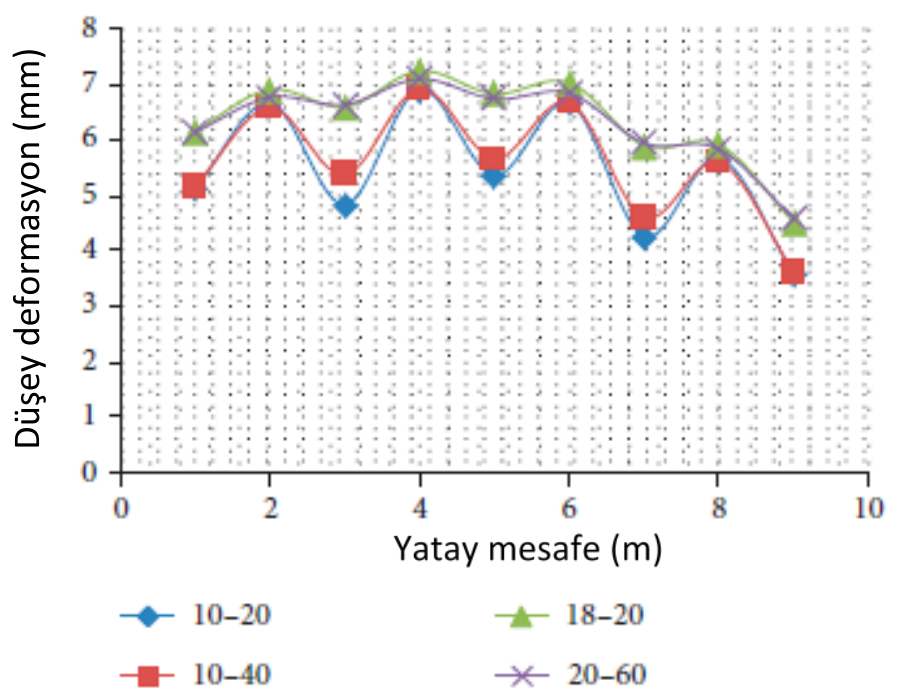

Şekil 1. Düşey deformasyonun yol uzunluğu ve tabaka kalınlığı ile değişimi (He ve Yang, 2018)

Asfalt karışım, bir çeşit çok fazlı kompozit heterojen malzemedir. Agregaların mekansal dağılımı kaplamanın iskeletsel homojenliğini önemli derecede etkiler. Kaba agreganın uzaysal dağılımı iyi değilse kaba agregaların kümelendiği alanlarda, nispeten daha büyük hava boşluk hacmi ve nispeten daha az asfalt bağlayıcı olur, asfalt karışımının yoğunluğu azalır ve geçirgenlik artar, bu da ciddi su hasarına neden olur. Bu nedenle, asfalt karışım homojenliğinin analizi ve değerlendirilmesi, toplu segregasyonun önlenmesi için bir anahtardır (Zhang vd., 2017).

$\mathrm{Bu}$ çalışmanın amacı, uygulama koşullarında karışım homojenitesinin kaplama kalınlığına bağlı olarak yoğunluk, bitüm içeriği ve agrega gradasyonu parametreleri ile değerlendirilmesidir. $\mathrm{Bu}$ amaçla, genellikle ağır taşıt park alanı olarak kullanılan yaklaşık $500 \mathrm{~m}$ uzunluğundaki bir yol kesimi üzerinde belirli aralıklarla alınan farklı kalınlıklardaki karot örneklerinin yoğunluk ve ekstraksiyon yöntemi ile belirlenen bitüm içerikleri ve agrega gradasyonları araştırılmıştır.

\section{Materyal ve Yöntem}

\subsection{Materyal}

Çalışmada kullanılan karot örnekleri Of-Çaykara yolu $2+500 \mathrm{~km}$ 'de yan yol olarak inşaa edilmiş yol kesiminden alınmıştır. Yol kesiminde, Karayolları Teknik Şartnamesine uygun aşınma tabakası Tip-1 tasarımı uygulanmıştır. Yaklaşık olarak 6 yıl hizmet vermiş yol kesimi üzerinden karot örnekleri alınarak laboratuvarda yoğunluk ve elek analizi yöntemleri ile karışım homojenitesi değerlendirmesi yapılmıştır.

Kaplama imalatında kullanılan bazalt agrega özellikleri Tablo 1'de tane boyutu dağılımları da Tablo 2 ve Şekil 2'de gösterilmiştir.

Tablo 1. Çalışmada kullanılan agregaların özellikleri

\begin{tabular}{ll}
\hline Agrega özelliği & Değer \\
\hline Aşınma kaybı (\%) & 18.1 \\
Hava etkilerine dayanıklılık (\%) & 1.43 \\
Su Absorbsiyon \% (kaba agrega) & 0.64 \\
Su Absorbsiyon \% (ince agrega) & 1.07 \\
Yassılık indeksi & 19.2 \\
\hline
\end{tabular}


Tablo 2. Agrega tane boyutu dağılımı

\begin{tabular}{cccc}
\hline $\begin{array}{c}\text { Elek } \\
\text { açıklığ1 } \\
(\mathrm{mm})\end{array}$ & $\begin{array}{c}\text { Karışım } \\
\text { \% geçen }\end{array}$ & $\begin{array}{c}\text { Tolerans } \\
\text { limitine } \\
\text { göre \% geçen }\end{array}$ & $\begin{array}{c}\text { Şartname } \\
\text { limiti } \\
\text { \% geçen }\end{array}$ \\
\hline 19 & 100 & 100.0 & 100 \\
12.5 & 90.8 & $86.8-94.8$ & $83-100$ \\
9.5 & 77.0 & $73.0-81.0$ & $70-90$ \\
4.75 & 46.1 & $42.1-50.1$ & $40-55$ \\
2.00 & 29.9 & $26.9-32.9$ & $25-38$ \\
0.425 & 13.5 & $10.5-16.5$ & $10-20$ \\
0.180 & 10.0 & $7.0-13.0$ & $6-15$ \\
0.075 & 6.7 & $4.7-8.7$ & $4-10$ \\
\hline
\end{tabular}

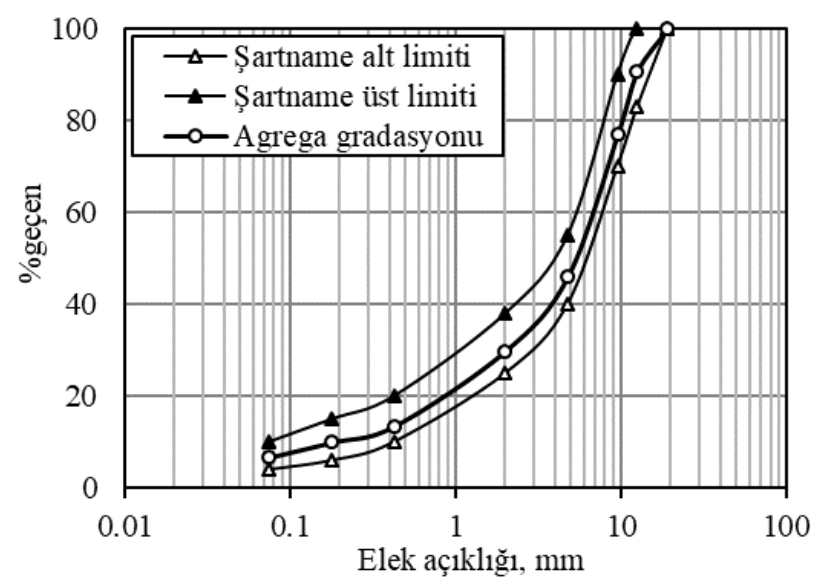

Şekil 2. Agrega gradasyon eğrisi ve şartname limitleri

Yol kaplama tasarımında 50/70 penetrasyon dereceli bitüm kullanılmıştır. Bitümün ve agregaların özgül ağırlıkları Tablo 3'te gösterilmiştir. Optimum bitüm içeriği ASTM D1559 standardına göre Marshall tasarım yöntemi ile \%5.20 olarak belirlenmiştir. Optimum bitüm içeriğinde boşluk oranı $\% 4$ ve pratik yoğunluk $2.493 \mathrm{gr} / \mathrm{cm}^{3}$ olarak belirlenmiştir.

Tablo 3. Agregaların ve bitümün özgül ağırlıkları

\begin{tabular}{lc}
\hline Agrega ve bitüm özelliği & Değer $\left(\mathrm{gr} / \mathrm{cm}^{3}\right)$ \\
\hline Kaba agrega & 2.785 \\
Kaba agrega (zahiri) & 2.835 \\
İnce agrega & 2.770 \\
İnce agrega (zahiri) & 2.855 \\
Filler (zahiri) & 2.871 \\
Bitüm özgül ağırlı̆̆ & 1.035 \\
\hline
\end{tabular}

Yaklaşık 500m uzunluğundaki yol kesiminden belirli aralıklarla 38 adet $150 \mathrm{~mm}$ çaplı karot örneği alınmıştır. Karot örneklerinin yoğunlukları belirlenmiş, kalınlıklarına göre gruplandırılarak ekstraksiyon yöntemi ile bitüm içerikleri hesaplanmıştır. Son olarak ta granülometrik analiz yapılarak kaplamanın karışım homojenitesi değerlendirilmiştir. Karot örneklerinden bir görüntü Şekil 2'de sunulmuştur.

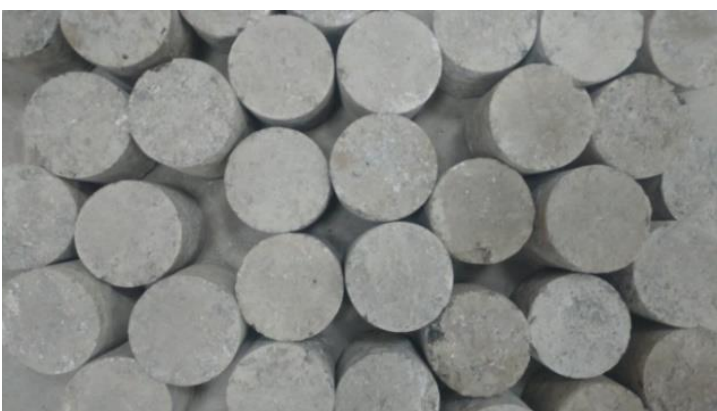

Şekil 2. Karot örneklerinden bir görüntü

\subsection{Yöntem}

Kaplamadan alınan karot örnekleri yıkanarak temizlenmiş, yıkama sırasında boşluklara dolan suyun buharlaşması için üç ay laboratuvarda bekletilmiştir. Karot boyları üç ölçümün ortalaması alınarak belirlenmiş ve küçükten büyüğe sıralı olarak numaralandırılmıştır. Yoğunluklar TS EN 12697-6 Prosedür B'ye göre hesaplanmıştır. Hesaplamalarda formül (1) kullanılmıştır.

$\rho_{\text {bssd }}=\frac{m_{1}}{m_{3}-m_{2}} \cdot \rho_{w}$

Burada;

$\rho_{\text {bssd }}$ : Hesaplanan yoğunluk, $\mathrm{Mg} / \mathrm{m}^{3}\left(\mathrm{~g} / \mathrm{cm}^{3}\right)$

$m_{1}$ : kuru örneğin kütlesi, $g$

$m_{2}$ : su içerisinde örneğin kütlesi, $g$

$m_{3}$ : Doygun yüzey kuru örneğin kütlesi, $\mathrm{g}$

$\rho_{w}$ : Test sicaklığında $\left(25^{\circ} \mathrm{C}\right)$ suyun yoğunluğu, $\mathrm{Mg} / \mathrm{m}^{3}$

Suyun $25^{\circ} \mathrm{C}$ sıcaklıktaki yoğunluğu 0.9971168 $\mathrm{g} / \mathrm{cm}^{3}$ alınarak karot yoğunlukları hesaplanmıştır.

Asfalt karışımların bitüm içeriği kaplamanın mekanik özellikleri ve dolayısıyla performansı üzerinde çok önemli bir etkiye sahiptir. Günümüzde asfalt plentleri çok etkili bir karıștırma yapabilseler bile taşıma, serme ve sıkıştırma aşamalarındaki olası operasyonel hatalar kaplamada farklı bitüm içeriklerine sebebiyet verebilmektedir. $\mathrm{Bu}$ nedenle bitüm içeriğinin hassas bir şekilde belirlenebilmesi önem arz etmektedir.

Bitüm içeriğinin belirlenmesinde çeşitli yöntemler kullanılabilmektedir. Çözücü ile ekstraksiyon en sık kullanılan yöntemdir. $\mathrm{Bu}$ yöntemde trikloretilen, benzen ve benzin gibi çözücüler kullanılmaktadır. Çözücüler asfalt karışım içerisindeki bağlayıcıyı çözer. Çözülmüs asfalt bağlayıcı filtre kağıdından süzülerek agrega karışımından ayrılır. $\mathrm{Bu}$ işlem için santrifüj ekstraktör kullanılır. 
Bitüm oranının belirlenmesinde kullanılan diğer bir yöntem yakma firını yöntemidir. Bu yöntemde yüksek sıcaklıklarda karışım içerisindeki bitüm yakılır ve geriye agregalar kalır. Ancak bu yöntemde bazı agregalar yanabilir veya kütle azalması olabilir. Nükleer asfalt içeriği ölçüm cihazı veya biyolojik çözme ile de bitüm muhtevası belirlenebilir. Nükleer cihazların radyoaktif özelliklerinden dolayı kullanımları sinırlıdır. Biyolojik çözme ise zaman alıcı bir yöntemdir (Jie vd., 2007).

$\mathrm{Bu}$ çalışmada, kaplamadan alınan karot örneklerinin bitüm içeriği TS EN 12697-1 yöntemine uygun olarak santrifüj ekstraksiyon yöntemi ile belirlenmiştir. Çözücü olarak trikloretilen soğuk uygulama ile kullanılmıştır. $\mathrm{Bu}$ yöntemde, bitümlü bağlayıcı çözülerek karışımdan ayrıldıktan sonra başlangıçtaki karışım kütlesine göre oluşan kütle kaybına bağlı olarak bitüm içeriği hesaplanmıştır.

Agrega gradasyonu ise ekstraksiyon kalıntısina yapılmıştır. TS EN 12697-1 standardına göre hazırlanan agrega karışımlarına TS EN 12697-2 yöntemine uygun olarak elek analizi yapılmıştır.

\section{Deney Sonuçları ve Tartışma}

Kaplamadan alınan karot örnekleri boyutlarına göre siralandiktan sonra numaralandırılarak yoğunluk hesaplaması yapılmıştır. Tablo 4'te karot örneklerinin yükseklikleri, yoğunlukları ve bitüm içerikleri gösterilmiştir.

Tablo 4. Karot örneklerinin yükseklik, yoğunluk ve bitüm içerikleri

\begin{tabular}{cccccccc}
\hline Karot No & $\begin{array}{c}\text { Yükseklik } \\
(\mathrm{cm})\end{array}$ & $\begin{array}{c}\text { Yoğunluk } \\
\left(\mathrm{gr} / \mathrm{cm}^{3}\right)\end{array}$ & $\begin{array}{c}\text { Bitüm içeriği } \\
(\%)\end{array}$ & Karot No & $\begin{array}{c}\text { Yükseklik } \\
(\mathrm{cm})\end{array}$ & $\begin{array}{c}\text { Yoğunluk } \\
\left(\mathrm{gr} / \mathrm{cm}^{3}\right)\end{array}$ & $\begin{array}{c}\text { Bitüm içeriği } \\
(\%)\end{array}$ \\
\hline 1 & 5.4 & 2.518 & 5.51 & 20 & 7.1 & 2.514 & 5.37 \\
2 & 5.6 & 2.523 & 5.48 & 21 & 7.1 & 2.519 & 5.25 \\
3 & 5.6 & 2.522 & 5.47 & 22 & 7.2 & 2.515 & 5.23 \\
4 & 5.8 & 2.515 & 5.43 & 23 & 7.2 & 2.508 & 5.48 \\
5 & 5.9 & 2.520 & 5.29 & 24 & 7.3 & 2.523 & 5.39 \\
6 & 6.1 & 2.521 & 5.39 & 25 & 7.3 & 2.513 & 5.43 \\
7 & 6.1 & 2.511 & 5.20 & 26 & 7.3 & 2.502 & 5.31 \\
8 & 6.3 & 2.517 & 5.23 & 27 & 7.4 & 2.516 & 5.27 \\
9 & 6.6 & 2.512 & 5.50 & 28 & 7.4 & 2.511 & 5.49 \\
10 & 6.7 & 2.513 & 5.46 & 29 & 7.5 & 2.515 & 5.24 \\
11 & 6.7 & 2.521 & 5.32 & 30 & 7.6 & 2.510 & 5.54 \\
12 & 6.8 & 2.511 & 5.23 & 31 & 7.7 & 2.503 & 5.34 \\
13 & 6.8 & 2.507 & 5.49 & 32 & 7.8 & 2.500 & 5.34 \\
14 & 6.9 & 2.510 & 5.22 & 33 & 8.0 & 2.515 & 5.53 \\
15 & 6.9 & 2.525 & 5.34 & 34 & 8.0 & 2.499 & 5.49 \\
16 & 6.9 & 2.518 & 5.53 & 35 & 8.1 & 2.511 & 5.52 \\
17 & 7.0 & 2.521 & 5.41 & 36 & 8.2 & 2.496 & 5.41 \\
18 & 7.0 & 2.509 & 5.28 & 37 & 8.3 & 2.497 & 5.32 \\
19 & 7.1 & 2.521 & 5.44 & 38 & 8.5 & 2.501 & 5.40 \\
\hline
\end{tabular}

Tablo 4'te verilen yoğunlukların yüksekliğe bağlı değişimini gösteren grafik Şekil 3'te sunulmuştur. Şekil 3'ten kaplama kalınlığının artmasıyla genel olarak yoğunlukların azalma eğiliminde olduğu görülmüştür. Ancak kalınlık ile yoğunluk arasında güçlü bir doğrusal ilişki oluşmamıştır. En güçlü ilişki $\left(R^{2}=0.4755\right)$ ikinci derece polinom ile elde edilmiştir.

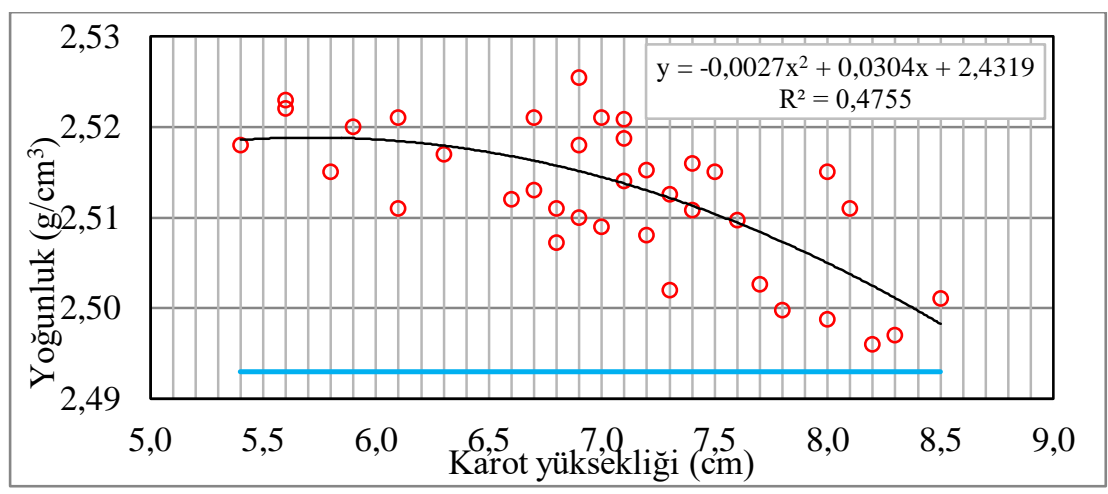

Şekil 3. Karot yüksekliği yoğunluk ilişkisi 
Polinom eğrisinden de görüldüğü gibi $5.5-6.5 \mathrm{~cm}$ kalınlık aralığında eğrinin eğimi düşük iken kalınlık arttıkça eğim de gittikçe artmıştır. Bu durum kaplama kalınlığının nispeten düşük olduğu durumlarda sıkıştırılabilirliğin daha kolay olduğunu ancak kalınlığı artmasiyla sıkıştırılabilirliğin de gittikçe zorlaştığı anlamına gelmektedir.

Bununla birlikte kaplamanın farklı noktalarından alınan aynı yükseklikteki karot örneklerinde farklı yoğunlukların oluştuğu da görülmüştür. Bu durum iki şekilde açıklanabilir. Karot örnekleri yaklaşık 6 yaşındaki kaplamadan alınmıştır. Kaplama, hizmet süresi içerisinde genellikle kamyon park alanı olarak kullanılmıştır. $\mathrm{Bu}$ süre içerisinde farklı yüklemelere maruz kalmış olabilir. İkinci bir ihtimal ise karışım homojenitesinin farklı olabileceğidir.

Karot örneklerinin yoğunlukları tasarımda belirlenen yoğunluk değerinden daha yüksek çıkmıştır. Daha ince olan örnekler daha yüksek değerler gösterirken kalınlık arttıkça yoğunluklar da tasarım yoğunluğuna yaklaşmıştır. Bu durum, kaplamanın hizmet süresi boyunca tekerlek yükleri altında sıkışmaya devam etmesiyle açıklanabilir.

Kalınlığa bağlı olarak bitüm içeriklerinin değişimi de Şekil 4'te gösterilmiştir. Ekstraksiyon deneyi sonrasında bulunan bitüm içerikleri karışım tasarımı ile bulunan bitüm içeriklerinden yüksek çıkmıştır. Ekstarksiyon yöntemi ile bitümün agregadan ayrılması sırasinda filler malzemenin bitüme karışarak filtreden süzülmesi sonucu bitüm içeriğinin yüksek çıkmış olabileceği düşünülmektedir. Bitüm içerikleri ile kaplama kalınlığı arasında bir ilişki kurulamamıştır. Ancak ortalama olarak değerlendirildiğinde bitüm içerikleri tasarım değerine $(\% 5.20)$ göre $\% 0.2$ daha büyük (ortalama \%5.40) hesaplanmıştır.

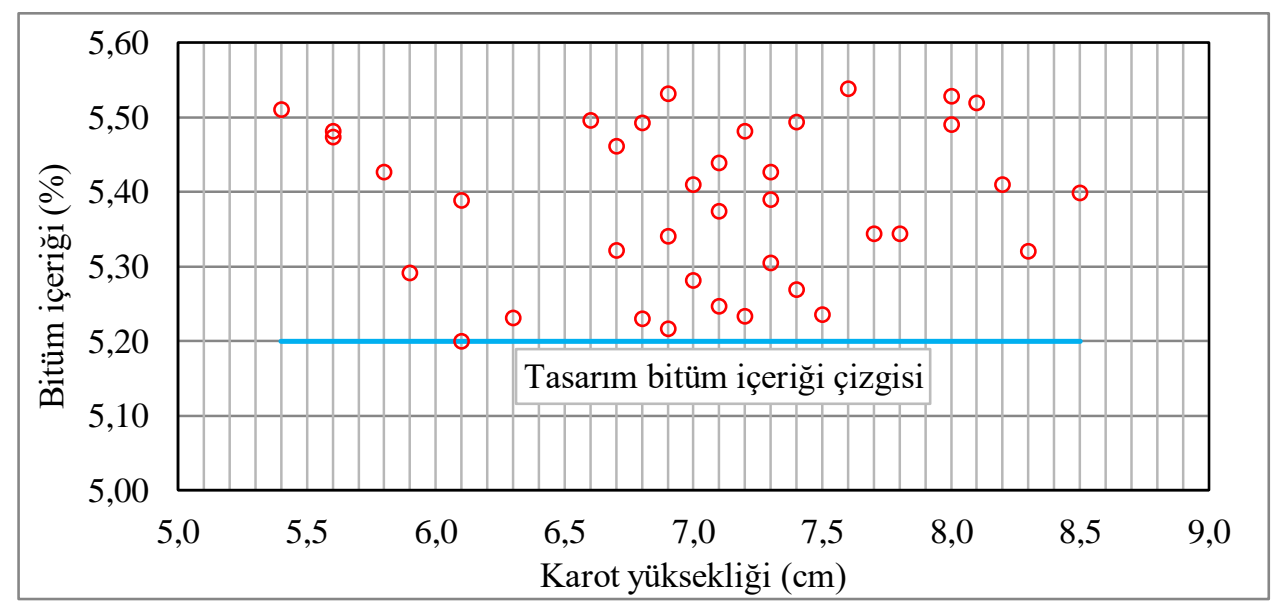

Şekil 4. Karot örneklerinin ekstraksiyon sonrası hesaplanan gradasyonları

Bitüm içeriği düşük olan örneklerin (örneğin 7 ve 14 numaralı örnekler) yoğunlukları da nispeten daha düşük çıkmıştır. Düşük bitüm içeriklerinde (optimum bitüm içeriğinin altında) karışımın sıkıştırılabilirliği azalacağından daha yüksek hava boşlukları oluşmaktadır. Yüksek hava boşluğu oranı karıșımın yoğunluğunu düşürmektedir. Ölçülen yoğunluklar ekstraksiyon yöntemi ile bulunan bitüm içeriklerini doğrular niteliktedir.

Eğer asfalt kaplamanın yoğunluğu çok düşük ise çeşitli hasar mekanizmaları gelişebilir. Tecrübeler düşük yoğunluğun yüksek permeabilite ile ilişkili olduğunu, bunun da donma çözülme hasarı kadar soyulma problemini de içeren çeşitli problemlere yol açabildiğini göstermektedir. Bunun yanı sıra yüksek yoğunlukla ilgili performans problemleriyle de karşılaşılmaktadır.
Uygulayıcılar genellikle optimum bitüm yoğunluğunun altında karışımlar ürettikleri için bu tür problemlerle daha az karşılaşılmaktadır. Çünkü zamanla trafik yükleri altında kaplama sıkışmaya devam etmektedir. Bitüm oranındaki artış yorulma ömründe ve tekerlek izinde artışa neden olmaktadır. Karıșıma bitüm ilave etmek (belirli bir orana kadar) karışımın uygulamada yoğunluğunu da arttırmakta, bu artış kaplama performansina olumlu yansimaktadır (Fisher vd., 2010).

Literatürdeki veriler, $\% 7$ hava boşluğu esas alındığında, hava boşluğundaki \%1'lik artışın kaplama ömründe \%10 azalmaya neden olduğunu göstermektedir. $\mathrm{Bu}$ nedenle hava boşluğu ve dolayısıyla yoğunluktaki en küçük değişiklik kaplama performansını önemli ölçüde etkileyebilir 
(Linden vd., 1988). Ekstraksiyon deneyi sonrasında bitümden arındırılmış agregalara elek analizi yapılarak elde edilen sonuçlar Tablo 5'te verilmiştir. Tablo 5'te her bir elekten geçen agregaların toplam agrega ağırlığına oranı gösterilmiştir.

Tablo 5. Karot örneklerinin elek analizi sonuçları

\begin{tabular}{lllllllllllllll}
\hline $\begin{array}{l}\text { Elek } \\
\text { Boyutu } \\
(\mathrm{mm})\end{array}$ & $\begin{array}{c}\text { Tasarım } \\
\text { Grad. }\end{array}$ & \multicolumn{1}{l}{ Karot örnek numaras1 } & 1 & 2 & 3 & 4 & 5 & 6 & 7 & 8 & 9 & 10 & 11 & 12 \\
\hline 19 & 100 & 100 & 100 & 100 & 100 & 100 & 100 & 100 & 100 & 100 & 100 & 100 & 100 \\
12.5 & 90.8 & 91.06 & 91.82 & 91.63 & 92.14 & 92.08 & 91.04 & 91.21 & 92.08 & 91.19 & 91.63 & 91.84 & 91.19 \\
9.5 & 77.0 & 78.56 & 77.79 & 79.43 & 78.89 & 78.73 & 79.66 & 78.97 & 79.94 & 79.12 & 78.12 & 78.92 & 78.96 \\
4.75 & 46.1 & 48.46 & 47.95 & 47.70 & 47.88 & 48.41 & 47.57 & 47.76 & 47.60 & 47.67 & 48.17 & 48.06 & 47.42 \\
2 & 29.9 & 30.38 & 30.67 & 30.04 & 30.08 & 29.54 & 29.49 & 30.33 & 30.24 & 31.10 & 29.67 & 30.66 & 29.41 \\
0.425 & 13.5 & 10.15 & 7.91 & 10.25 & 7.04 & 7.32 & 8.66 & 7.56 & 8.46 & 9.09 & 9.15 & 9.32 & 8.20 \\
0.18 & 10.0 & 6.11 & 7.66 & 6.00 & 6.24 & 7.86 & 7.74 & 7.11 & 7.09 & 6.34 & 7.64 & 6.19 & 7.63 \\
0.075 & 6.7 & 5.74 & 3.98 & 5.32 & 5.66 & 5.10 & 5.66 & 5.63 & 4.66 & 4.35 & 4.23 & 4.08 & 4.62 \\
\hline
\end{tabular}

\begin{tabular}{|c|c|c|c|c|c|c|c|c|c|c|c|c|c|}
\hline \multirow{2}{*}{$\begin{array}{l}\text { Elek } \\
\text { Boyutu } \\
(\mathrm{mm})\end{array}$} & \multicolumn{13}{|c|}{ Karot örnek numarası } \\
\hline & 13 & 14 & 15 & 16 & 17 & 18 & 19 & 20 & 21 & 22 & 23 & 24 & 25 \\
\hline 19 & 100 & 100 & 100 & 100 & 100 & 100 & 100 & 100 & 100 & 100 & 100 & 100 & 100 \\
\hline 12.5 & 91.78 & 91.39 & 91.31 & 91.03 & 91.69 & 92.09 & 92.11 & 91.53 & 91.48 & 91.89 & 91.54 & 92.18 & 91.74 \\
\hline 9.5 & 79.32 & 79.73 & 79.32 & 79.15 & 78.74 & 78.42 & 77.80 & 78.49 & 79.86 & 79.74 & 78.01 & 77.87 & 77.55 \\
\hline 4.75 & 47.06 & 48.02 & 47.34 & 48.26 & 47.65 & 47.00 & 47.68 & 47.64 & 48.38 & 47.42 & 47.33 & 47.77 & 48.30 \\
\hline 2 & 30.04 & 30.96 & 30.34 & 30.89 & 30.79 & 29.74 & 30.89 & 30.23 & 30.98 & 30.54 & 31.17 & 30.75 & 29.90 \\
\hline 0.425 & 7.06 & 7.67 & 7.84 & 6.80 & 8.05 & 8.71 & 8.45 & 7.48 & 7.60 & 7.43 & 8.02 & 7.94 & 7.45 \\
\hline 0.18 & 7.08 & 6.75 & 6.82 & 6.93 & 7.25 & 7.20 & 7.17 & 7.71 & 7.47 & 7.43 & 7.92 & 7.55 & 7.04 \\
\hline 0.075 & 5.41 & 5.02 & 5.29 & 4.44 & 4.93 & 5.14 & 5.30 & 4.86 & 4.33 & 5.39 & 3.95 & 5.12 & 4.40 \\
\hline \multirow{2}{*}{$\begin{array}{l}\text { Elek } \\
\text { Boyutu } \\
(\mathrm{mm})\end{array}$} & \multicolumn{13}{|c|}{ Karot örnek numarası } \\
\hline & 26 & 27 & 28 & 29 & 30 & 31 & 32 & 33 & 34 & 35 & 36 & 37 & 38 \\
\hline 19 & 100 & 100 & 100 & 100 & 100 & 100 & 100 & 100 & 100 & 100 & 100 & 100 & 100 \\
\hline 12.5 & 91.84 & 91.19 & 92.13 & 91.54 & 91.25 & 91.33 & 91.73 & 91.84 & 91.99 & 91.66 & 91.53 & 91.31 & 92.17 \\
\hline 9.5 & 78.91 & 79.54 & 77.74 & 79.85 & 78.21 & 77.83 & 79.26 & 77.64 & 78.10 & 79.08 & 78.83 & 79.58 & 79.16 \\
\hline 4.75 & 47.47 & 48.33 & 48.44 & 47.35 & 48.14 & 48.39 & 48.26 & 47.93 & 47.43 & 48.07 & 47.66 & 48.44 & 47.90 \\
\hline 2 & 29.82 & 29.45 & 30.52 & 29.76 & 30.89 & 31.25 & 30.04 & 30.94 & 29.83 & 30.70 & 30.97 & 30.62 & 29.99 \\
\hline 0.425 & 9.26 & 7.70 & 6.83 & 7.82 & 7.51 & 8.98 & 8.50 & 8.81 & 9.85 & 7.99 & 8.94 & 8.99 & 7.28 \\
\hline 0.18 & 5.81 & 6.82 & 6.80 & 7.92 & 7.84 & 6.39 & 7.74 & 7.21 & 7.19 & 7.53 & 6.78 & 7.43 & 6.05 \\
\hline 0.075 & 5.46 & 4.82 & 5.32 & 5.47 & 5.54 & 4.72 & 3.96 & 5.02 & 5.39 & 4.32 & 5.51 & 5.62 & 4.61 \\
\hline
\end{tabular}

Elek analizi sonuçları değerlendirilirken karot örnekleri yüksekliklerine göre gruplandırılarak ortalama gradasyon eğrileri oluşturulmuştur. 5.4$6 \mathrm{~cm} ; 6-6.5 \mathrm{~cm} ; 6.5-7 \mathrm{~cm} ; 7-7.5 \mathrm{~cm} ; 7.5-8 \mathrm{~cm}$ ve $8-$ $8.5 \mathrm{~cm}$ olmak üzere 6 grup oluşturulmuştur. Ekstraksiyon sonucunda oluşturulan ortalama gradasyon eğrileri ile tasarım gradasyon eğrileri Şekil 5'te karşılaştırılmıştır.

Șekil 5'ten görüldüğü gibi $5.4 \mathrm{~cm}$ 'den $8.5 \mathrm{~cm}$ 'ye kadar değişen kalınlıklarda ekstraksiyon sonucu elde edilen agrega gradasyonu önemli bir șekilde değişmemiş, eğriler birbirine çok yakın oluşmuştur. Ancak tasarım gradasyonuyla karşılaştırıldığında kaba agrega oranında azalma olduğu görülmüsstür. Karot örneklerinin alınması sırasında agregaların kesilmiş olması bu sonuca yol açmış olabilir. Ayrıca asfalt karışım hazırlama ve sıkıştırma aşamalarında veya ekstraksiyon sürecinde agregaların kırılmış veya aşınmış olma ihtimali de bulunmaktadır. 


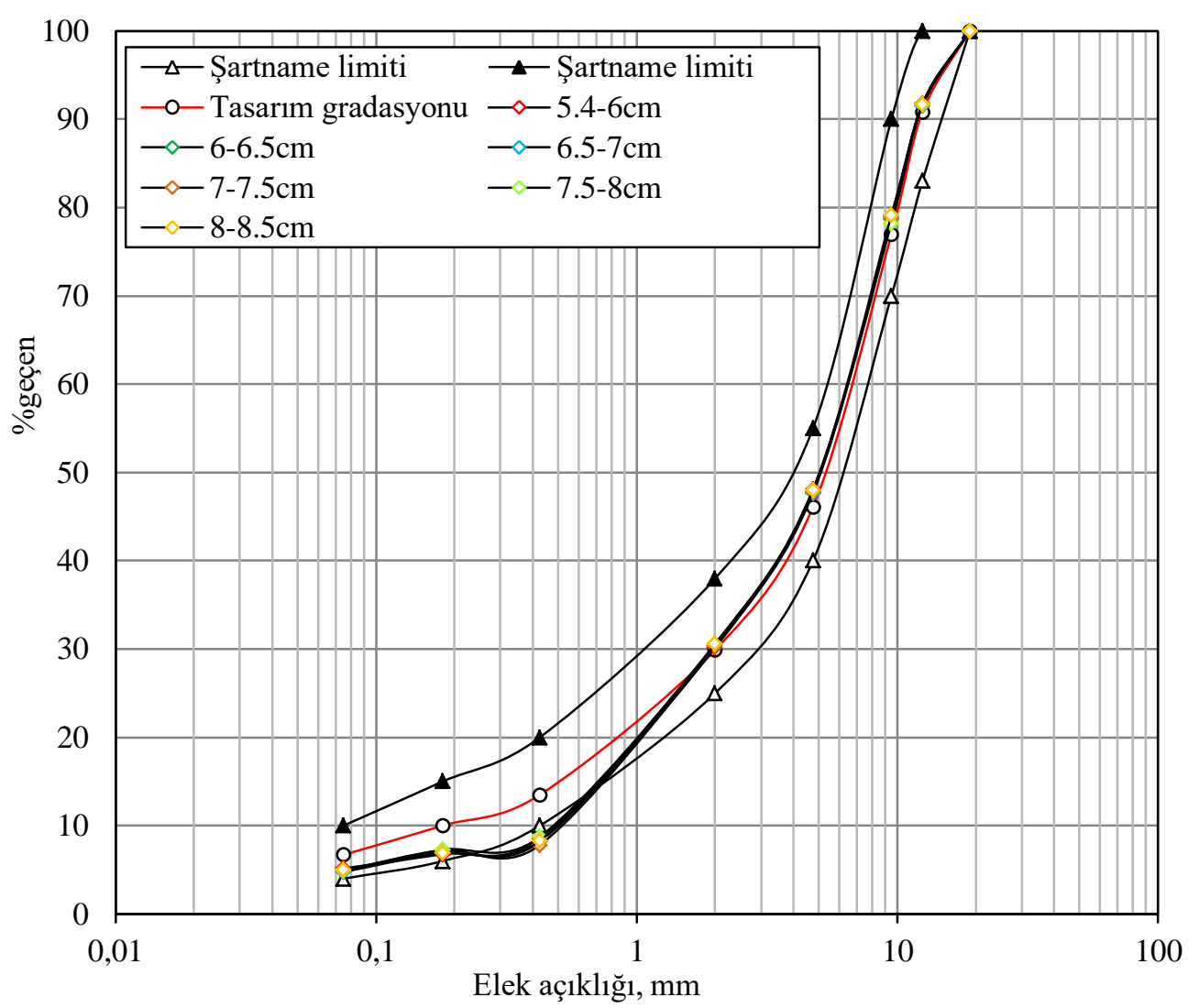

Şekil 5. Gradasyon eğrilerinin kaplama kalınlığına bağlı olarak değişimi

Agrega gradasyonu asfalt kaplamaların mekanik özelliklerini önemli ölçüde etkilemektedir. Mekanik özellikler, diğer harici etkenlerle kaplamadaki bozulma mekanizmalarının gelişimini etkilemektedir. Kaplama kalınlığına bağlı olarak gradasyon homojenitesinin araştırılması kompleks bir konudur. Gerek aynı elek açıklı̆̆ındaki (19-12.5mm; 12.5-9.5mm vb.) agrega gruplarının homojen olarak dağılıp dağılmadığı konusu, gerek agrega köşelilikleri, agrega porozitesi ve bitüm emme durumu ekstraksiyon yöntemini ve sonrasında yapılan elek analizini ve bu analizler sonrasinda yapilan göreceli karşılaştırmayı zorlaştırmaktadır. $\mathrm{Bu}$ anlamda daha hassas yöntemlerin kullanılması anlamlılık düzeyi daha yüksek sonuçlara ulaşılmasını kolaylaştırabilir. Yapılan çalışmada elde edilen gradasyon eğrileri çok yakın oluşmuş kaplama kalınlığına bağlı olarak farklılık anlamında bir fikir verememiştir.

Homojensizlik türlerinden birisi olan segregasyon çoğu kaplamada zayıf performansların oluşmasına neden olur. Ancak günümüzde kaplamanın performansında düşüşe yol açmak için ne kadar segregasyon olması gerektiğini belirlemeye yönelik bir prosedür bulunmamaktadır. Alabama bölgesinde beş değişik yol ve deneme kesiminde segregasyonun kaplama performans1 üzerinde etkileri araştırılmıştır. Bulgular, No.4 elekten geçen agrega yüzdesindeki değişimin \%10-12'den daha büyük olması durumunda önemli sökülmelere yol açabileceğini göstermiştir. Test bölgesinde, ortalama bitüm içeriğinden daha düşük oranda bitüm içeren kaplama bölgelerinin segregasyona uğradığı, segrege olmuş alanların ortalama kaplama yoğunluğundan daha düşük yoğunluğa sahip olduğu, 2-3 yıl sonra kaplamanın segrege bölgelerinin yüzey dokusunun farklılaştığ 1 ve sökülme belirtileri oluştuğu görülmüştür (Cross ve Brown, 1993).

Yapılan çalışmada No 4 elekten geçen agrega oranlar1 tasarım agrega oranları ile karşılaştırıldığında \%3'ün altında farklılıklar görülmüştür. Karot örnekleri alınması sırasında kaplama yüzeyinde gözle görülebilir bir segregasyona rastlanılmamıştır. Soyulma, çatlama veya çatlama problemlerinden herhangi biri de belirlenememiştir.

Uygulama kesimlerindeki asfalt betonunda bitüm içeriğinin belirlenmesi üzerine gerçekleştirilen bir çalışmada kireçtaşı ve geri kazanılmış materyal kullanılan iki asfalt karışım araştırılmıştır. Araştırma sonuçları, kireçtaşı karışımı ile yapılan karışımda bitüm yüzdesinin deney öncesine göre $\% 0.26$ ve geri kazanılmış asfalt karışımı ile 
yapılanda da \%0.31 fazla çıktığını ortaya koymuştur (McGraw, vd., 2001). Bu çalışmada da literatürü doğrular veriler elde edilmiştir.

Ekstraksiyon yöntemiyle deney öncesi ve sonrasındaki gradasyonların karşılaştırıldığ çalışmada, deney öncesi ve sonrasına göre gradasyon bakımından en fazla bozulmanın $1.18 \mathrm{~mm}$ ile $2.36 \mathrm{~mm}$ elekler arasında olduğu görülmüştür. Filler oranındaki değişimin karışımın katkı maddesi içerip içermemesine göre değişkenlik gösterdiği anlaşılmıştır (Namlı, 2005). $\mathrm{Bu}$ çalışmada da benzer sonuçlara ulaşılmıştır. Tasarım gradasyonu baz alındığında $0.18 \mathrm{~mm}$ ile $2.0 \mathrm{~mm}$ elekler arasında en yüksek bozulma gerçekleşmiştir. $0.425 \mathrm{~mm}$ açıklıklı elekte tasarım gradasyonuna göre geçen agrega oran $\% 13.5$ iken deneyler sonucu elde elde edilen ortalama oran \%8.58 olmuştur. 38 örneğin tamamında benzer eğriler elde edilmiştir.

\section{Sonuçlar}

$\mathrm{Bu}$ araştırmada, asfalt kaplamalarda karışım homojenitesi kaplama kalınlığına bağlı olarak bitüm içeriği, agrega gradasyonu ve yoğunluk parametreleriyle değerlendirilmiştir. Ağır araçların park alanı olarak kullandığı uygulama sahasından, kaplama serildikten yaklaşı 6 yıl sonra, belirli aralıklarla karot örnekleri alınmıştır. Bitüm içeriği TS EN 12697-1 standardına göre ve elek analizi de ekstraksiyon sonrası kalıntı agregalara TS EN 12697-2 standard1 ile yapılmıştır. Karot yoğunlukları TS EN 12697-6 Metod B'ye göre belirlenmiştir. Gerçekleştirilen deneysel çalışmaların sonucunda aşağıdaki sonuçlara varılmıştır.

Uygulama sahasından alınan karot örneklerinin tamamının yoğunlukları tasarım yoğunluğunun üzerinde olmasına rağmen kaplama kalınlığ arttıkça ortalama yoğunluklar da azalmaktadır. Kaplama kalınlığ $6.5 \mathrm{~cm}$ değerine çıkıncaya kadar yoğunluk eğilim çizgisinde önemli bir azalma oluşmamakta ancak $6.5 \mathrm{~cm}$ 'den sonra yoğunluklar da hızla azalma eğilimine girmektedir. Kaplama aynı kalınlıkta olsa bile yoğunluk değerleri farklılıklar gösterebilmektedir.

Ekstraksiyon yöntemi ile bulunan bitüm içerikleri ile kaplama kalınlığı arasında yüksek korelasyonlu bir ilişki kurulamamıştır. Karot örneklerinin bitüm içerikleri (\%5.38) tasarım bitüm içeriğinin (\%5.2) üzerinde bulunmuştur. Ancak bitüm içeriği düşük olan örneklerin genellikle yoğunlukları da düşük gerçekleşmiştir.
Ekstraksiyon yöntemi sonucu oluşan agrega gradasyonları kaplama kalınlığına göre değerlendirilmiş ancak gradasyonlar bibirlerine göre çok yakın oluşmuştur. Bütün örneklerde tasarım gradasyonuna göre kaba agrega oranında çok az bir azalma oluşurken $0.18 \mathrm{~mm}$ ile $2.0 \mathrm{~mm}$ elek aralığında tasarım gradasyonuna göre \% 4.92 azalma ile en büyük bozulma gerçekleşmiştir.

\section{Kaynaklar}

ASTM D 1559-89, 1992. Standard Test Method for Resistance to Plastic Flow of Bituminous Mixtures Using Marshall Apparatus, Annual Book of ASTM Standards USA.

Cross, S.A. ve Brown, E.R. 1993. Effect of Segregation on Performance of Hot-Mix. Asphalt Transportation Research Record. 1417, 117126.

Fisher, J., Graves, C., Blankenship, P., HakimzadehKhoee, S. ve Anderson, R. M., 2010. Factors Affecting Asphalt Pavement Density and the Effect on Long Term Pavement Performance. Kentucky Transportation Center Research Report. 60. KTC-10-05-RSF14-05-1F, https://uknowledge.uky.edu/ktc_researchreports 160

He, D., ve Yang, W., 2018. Effect of Thickness of Gravel Base and Asphalt Pavement on Road Deformation, Advances in Civil Engineering, 17

Jie, W. ve Wei, W. 2007. Cheng Jianchuan, Gong Yongfeng, Jiang Dongfang and Zhou Chaohui, primary research on a binder extraction method for asphalt mix modified by using seam asphalt mix modifier, Proceedings of the 26th Southern African Transport Conference (SATC 2007), July 2007 Pretoria, South Africa s.794-800.

Linden, R.N., Mahoney, J.P. ve Jackson, N.C., 1988. Effect of Compaction on Asphalt Concrete Performance. Transportation Research Record. 1217, 20-28.

McGraw, J., Iverson, D., Schmidth, G. ve Olson, J., 2001. Selection of an Alternative Asphalt Extraction Solvent, Minnesota Department of Transportation, St. Paul, Minnesota.

Meegoda, J.N., Geoffrey, M. R., Andris J., Chamil, H. H., Nishantha, B. ve Nicholas, G., 2003. Detection of surface segregation using LASER. TRB, National Research Council, Washington, D.C.

Namlı, R., 2005. Sıkıştırılmış Asfalt Betonun Bitüm Yüzdesinin Tayini. Fırat Üniversitesi Fen ve Mühendislik Bilimleri Dergisi. (4), 693-698. 
Peng, Y. ve J. Sun, L. 2009. Towards an Index of Asphalt Mixture Homogeneity. Road Materials and Pavement Design, 10:3, 545-567.

Sefidmazgi, N.R., Tashman, L. ve Bahia, H. 2012. Internal structure characterization of asphalt mixtures for rutting performance using imaging analysis, Road Materials and Pavement Design, 13, 21-37.

Stroup-Gardiner, M. ve Brown, E. R., 2000. Segregation in Hot Mix asphalt Pavements. NCHRP Report 441, National Cooperative Highway Research Program, Transportation Research Board, National Research Council, Washington, D.C. s.32-81.

Stroup-Gardiner, M., Law, M. ve Nesmith, C., 2000. Using Infrared Thermography to Detect and Measure Segregation in Hot Mix Asphalt Pavements, International Journal of Pavement Engineering, 1:4, 265-284.

ter Huerne, H. L., Miller, S. R., ve Doree, A. G. 2009. Monitoring hot mix asphalt temperature to improve homogeneity and pavement quality. The sixth international conference on maintenance and rehabilitation of pavements and technological control, July 2009, Torino, Italy s. 556-565.

Türk Standartları Enstitüsü, 2013. TS EN 12697-1. Bitümlü karışımlar-Sıcak asfalt karışımları için deney yöntemleri-Bölüm 1:Çözünür bağlayıcı içeriği.

Türk Standartları Enstitüsü, 2015. TS EN 12697-2. Bitümlü karışımlar-Sıcak asfalt karışımları için deney yöntemleri-Bölüm 2: Tanecik büyüklüğü dağılımının tayini.

Türk Standartları Enstitüsü, 2012. TS EN 12697-6. Bitümlü karışımlar-Sıcak asfalt karışımlarDeney yöntemleri-Bölüm 6: Bitümlü deney numunelerinin yı̆̆ın yoğunluğunun tayini.

Wang, D.Y., Li, W.J. ve Zhang, X.N., 2004. Evaluation and Measurement of Asphalt Pavement Surface Texture Depth with Digital Image Technique. Journal of South China University of Technology (Natural Science), 32, 42-45.

Wolff, T.F., Baladi, G.Y. ve Change, C. M., 1997. Test method to determine the extent of segregation in bituminous mixtures. Michigan State University, Pavement Research Center for Excellence.

Zhang, J., Liu, H., Wang, P., Pei, J., Bao, D. Ve Jin, L., 2017. Evaluation of aggregate gradation and distributing homogeneity based on the images of asphalt mixture, Road Materials and Pavement Design, 18, 119-129. 